\title{
A REINVENÇÃO DAS CIDADES NA VIRADA DE SÉCULO: AGENTES, ESTRATÉGIAS E ESCALAS DE AÇÃO POLÍTICA ${ }^{1}$
}

\author{
Fernanda Sánchez \\ Universidade Federal do Rio de Janeiro
}

\begin{abstract}
RESUMO
Tomando como pano de fundo a globalização, o presente artigo procura mostrar que as mudanças impulsionadas por este fenômeno não se restringem ao mundo econômico, mas afetam a produção do espaço urbano e atingem diretamente a formulação e legitimação de paradigmas nas políticas urbanas. Diante dessa constatação, procurou-se enfatizar a mútua dependência entre os procedimentos materiais e simbólicos tomados aqui como estratégias de agentes envolvidos nos processos de reestruturação urbana. A abordagem proposta enfatiza a articulação entre os interesses globais e a formação de um mercado mundial de cidades.
\end{abstract}

PALAVRAS-CHAVE: reestruturação urbana; cidade-mercadoria; patriotismo de cidade; luta simbólica.

\section{A CIDADE-MERCADORIA E AS NOVAS ESTRATÉGIAS ESPACIAIS}

As chamadas "cidades-modelo" são imagens de marca construídas pela ação combinada de governos locais, junto a atores hegemônicos com interesses localizados, agências multilaterais ${ }^{2}$ e redes mundiais de cidades. A partir de alguns

\footnotetext{
1 Uma primeira versão deste texto foi apresentada na sessão “Ambiente urbano: representação e poder" durante o Simpósio Cidade e poder, realizado entre 23 e 24 de abril de 2001 na Universidade Federal do Paraná, promovido pela Revista de Sociologia e Política e pelo Grupo de Estudos Cidade, Poder e Sociedade, sob coordenação do Prof. Dr. Nelson Rosário de Souza. O texto recolhe argumentos de duas recentes comunicações de congressos, "La reinvención de los lugares: relaciones entre cultura y economía en los procesos de reestructuración urbana” (8aㅡ EGAL, Santiago de Chile, março de 2001) e "Cidades reinventadas para um mercado mundial: estratégias trans-escalares nas políticas urbanas" (9aㅡ ENANPUR, Rio de Janeiro, maio de 2001). A versão revisada recupera comentários e sugestões dos pareceristas da Revista de Sociologia e Política, além de questões surgidas no debate por ocasião do supracitado Simpósio.

2 Agências multilaterais são organismos de caráter internacional e ação global, que operam como centros de pensamento, difusão e financiamento de políticas públicas: BID, BIRD Banco Mundial, a ONU - Organização das Nações Unidas e suas agências (p. ex.: Agência HABITAT, CENUEH - Centro das Nações Unidas para os Assentamentos Humanos). Seu poder político está associado à atuação simultânea em diversas escalas: nacional e supranacional, regional e local.
}

centros de decisão e comunicação que, em variados fluxos e interações, parecem conformar um campo político de alcance global, os atores que participam desse campo realizam as leituras das cidades e constroem as imagens, tornadas dominantes mediante estratégias discursivas, meios e instrumentos para sua difusão e legitimação em variadas escalas.

Entretanto, quando tomadas isoladamente, as imagens das "cidades-modelo" parecem, para o senso comum, apresentar dito estatuto de "modelos" como resultado apenas do desempenho dos governos das cidade que, através de "boas práticas", conseguiram destacar-se na ação urbanística, ambiental ou nas práticas de gestão das cidades. Essa aparência constrói a representação do processo de transformação de determinados projetos de cidade em "modelos", como processo que se dá de dentro para fora, como se fosse construído apenas e essencialmente a partir da ação local dos governos e cidadãos e, posteriormente, descoberto por agentes externos, difundido em outros âmbitos e escalas.

No caso de Curitiba, a essa leitura imediata contrapõem-se outras, que se têm consubstanciado em trabalhos situados no campo da crítica ao modelo, e que dão visibilidade analítica ao conjunto de agentes das elites locais e às suas estratégias políticas e territoriais para explicar as possibilidades 
de realização histórica do projeto de modernização urbana (SÁNCHEZ, 1997; SOUZA, 1999; OLIVEIRA, 2000). Além dos atores locais, um conjunto de agentes e estratégias territoriais interescalares comparecem para erigir a imagem da "cidade-modelo", numa rede que, ao ser descoberta, evidencia um complexo mercado no qual as imagens são construídas e postas em circulação em variadas escalas (local, nacional e internacional), com mútuas influências de diversa ordem (SÁNCHEZ, 1997; SÁNCHEZ \& MOURA, 1999).

Efetivamente, o processo de produção do espaço social é ao mesmo tempo objetivo e subjetivo. Como parte da nova racionalidade do capitalismo, capaz de potencializar a eficiência econômica e a reorganização territorial, são introduzidas formas modernas de dominação e técnicas de manipulação cultural (BOURDIEU, 1998; SANTOS, 2000). Deste modo, o espaço toma forma também através de representações e imagens adequadas, o que explica a importância que vem adquirindo o city marketing como instrumento das políticas urbanas.

Assim, a retórica planetária dos atores hegemônicos associados ao que seria um "governo do mundial"3 (PARAIRE, 1995), contribui para a realização dos imperativos do capitalismo atual e da reestruturação econômica global. Trata-se de uma retórica persuasiva que, em sua vertente urbana, configura uma agenda para as cidades, tornada dominante, com pautas definidas para ações e programas, em uma afirmação política da hegemonia do pensamento e ação sobre as cidades. Como instrumento de consolidação dessa agenda urbana, são desenvolvidas políticas de promoção e legitimação de certos projetos de cidade. Esses projetos são difundidos como emblemas da época presente. Sua imagem publicitária são as chamadas "cidades-modelo" e seus pontos de irradiação coincidem com as instâncias políticas de produção de discursos: governos locais em associação com as mídias; instituições supranacionais, como a Comunidade Européia e agências multilaterais.

É por intermédio dessas instâncias e atores dominantes que os discursos dão-se como "inteligência global" (SANTOS, 2000, p. 100), exercida com base em um conjunto de parâmetros

3 Para o autor, entram nessa categoria as agências multilaterais como o FMI, a OMC, o Banco Mundial e a ONU. arbitrários que medem, avaliam e classificam cada projeto de modernização urbana com pretensões de reinserção global. Às relações de força entre os atores que orientam as escolhas econômicas e espaciais são acrescidas as relações de força propriamente simbólicas, capazes de disputar a construção e a difusão de "discursos fortes" (Goffmann, apud BOURDIEU, 1998, p. 136) junto a imagens fortes, frutos dos arranjos de poder que compareceram para produzi-los.

A análise de diversas publicações e documentos permite identificar, de fato, um grande comprometimento das agências de cooperação e instituições multilaterais com a difusão dos chamados "modelos" e seu ideário, dentre os quais destacamos, por exemplo, para o chamado "modelo-Barcelona", a obra Barcelona: un modelo de transformación urbana publicada pelo Ayuntamiento de Barcelona e Oficina Regional para América Latina e Caribe do Programa de Gestão Urbana das Nações Unidas, Programa das Nações Unidas para o Desenvolvimento - PNUD e Banco Mundial. Já para o caso do "modelo-Curitiba", neste texto também focalizado, é notável a sequiência de premiações outorgadas à Prefeitura Municipal pelas mesmas agências, além de destaques em seus relatórios anuais e numerosos artigos de difusão internacional elaborados por consultores do Banco Mundial e da ONU (SÁNCHEZ, 2001).

A identificação desses elos políticos entre as agências multilaterais de cooperação e alguns dos principais ideólogos encarregados da difusão do "novo modelo de gestão urbana" (constitutivamente vinculado às representações e práticas da Cidade-mercadoria), permite-nos o entendimento das conexões entre o chamado "pensamento global" e a ideologia neoliberal: "un gouvernement mondial en formation qui a trouvé dans la 'pensée globale' le masque scientifique nécessaire à son idéologie néolibérale" (PARAIRE, 1995, p. 180) ${ }^{4}$. De fato, os consultores alçados à condição de $e x$ perts internacionais, e sua atuação junto a organismos supranacionais, parecem desempenhar um importante papel na difusão e legitimação políticoideológica da idéia de cidade transformada em mercadoria. A importância e alcance dessa ação

\footnotetext{
4 "Um governo mundial em formação que tem encontrado no 'pensamento global' a máscara científica necessária à sua ideologia neoliberal”.
} 
combinada parece estar relacionada com a capacidade dos atores na articulação de diferentes escalas de ação política.

Através da análise de alguns processos de reestruturação urbana da década de 90 , em sua relação com os respectivos governos de cidade e suas políticas urbanas ${ }^{5}$, é possível identificar interessantes convergências. Essas convergências dizem respeito às estratégias utilizadas pelo poder político para "vender" as cidades. De fato, a partir de um determinado momento histórico, aqui identificado com os anos 90, as cidades passaram a ser "vendidas" de modo semelhante, o que sugere que o espaço das cidades se realiza agora enquanto mercadoria.

A transformação das cidades em mercadorias vem indicar que o processo de mercantilização do espaço atinge outro patamar, produto do desenvolvimento do mundo da mercadoria, da realização do capitalismo e do processo de globalização em sua fase atual. A existência de um mercado de cidades, como um fenômeno recente, mostra a importância cada vez maior do espaço no capitalismo - a orientação estratégica para a conquista do espaço, que agora alcança cidades como um todo, postas em circulação num mercado mundial - evidencia a produção global do espaço social.

A nova inspiração encontrada pelo capitalismo na conquista do espaço compreende a compra e venda do espaço na escala mundial. Essa orientação estratégia, como afirma Lefebvre (1998), tem muito mais importância que a simples venda de parcelas do espaço, pois procura realizar uma reorganização abrangente da produção subordinada às cidades e aos centros de decisão. Aí parece estar o que tem de novo o fenômeno do mercado de cidades: a produção global do espaço.

Essa estratégia global encontra uma nova dinâmica para a reprodução do capitalismo: a construção da cidade-mercadoria que, sob a égide do poder político dos governos locais, perfila-se através dos processos de reestruturação urbana (como exigência da economia competitiva) e através da construção de imagem para vendê-la,

5 Particularmente nas cidades de Curitiba (Brasil) e Barcelona (Espanha), mas também em cidades francesas como Montpellier, Lille e Nantes, inglesas como Oxford e Manchester, e norte-americanas como Baltimore, Boston e Chicago. para inseri-la no mercado. Como mercadoria especial, envolve estratégias especiais de promoção: são produzidas representações que obedecem a uma determinada visão de mundo, são construídas imagens-síntese sobre a cidade e são criados discursos referentes à cidade, encontrando na mídia e nas políticas de city marketing importantes instrumentos de difusão e afirmação. As representações do espaço e, baseadas nelas, as imagenssíntese e os discursos sobre as cidades, fazem parte, pela mediação do político, dos processos de intervenção espacial para renovação urbana.

As imagens-síntese e os discursos sobre as cidades referem-se a estratégias baseadas na racionalidade dos processos de reprodução da economia global. Desse modo, estão referidas a estratégias globais. Imagens e discursos baseiamse em uma visão de mundo que justifica e permite a realização das necessidades impostas pelo estágio atual da produção, aquele que se refere à construção do mercado mundial e do espaço mundial. Sob a égide da globalização, transformada em paradigma de entendimento do mundo moderno, constrói-se um discurso que a justifica e que está na base de sua sustentação.

A fase atual do capitalismo só se realiza produzindo um novo espaço, pressionado pelas novas exigências da acumulação, mediante suas lógicas e estratégias à escala mundial. Na produção desse espaço operam agentes e interesses combinados em diferentes campos políticos e arranjos territoriais para cada caso. Sujeitos, instituições, práticas e produtos circulam, de maneira relacionada, no âmbito de diferentes mercados, materiais e símbolos. Efetivamente, a análise do mercado de cidades permite identificar a produção, circulação e troca de bens materiais junto à produção, circulação e troca de imagens, linguagens publicitárias e discursos. Assim, o mercado mundial de cidades é movido por e, ao mesmo tempo, movimenta alguns outros mercados:

a) mercado para empresas com interesses localizados: empresas e corporações avaliam, em detalhe, pequenas diferenças entre lugares para tomar decisões locacionais. O elenco de fatores locacionais é cuidadosamente mensurado por empresas vinculadas ao capital financeiro, industrial, comercial e de serviços como também é avaliado na localização de novas sedes de organismos internacionais. As diferenças são submetidas à ordem do capital que tira proveito delas. Nesse sentido é que vários autores (HARVEY, 1994; 
SANTOS, 1996) procuram mostrar que o espaço é, na atual fase de desenvolvimento do capitalismo, mais importantes do que nunca;

b) mercado imobiliário: a crescente mobilidade do capital imobiliário permite fluidez no agenciamento de grandes operações localizadas, com investimentos de capital internacional ${ }^{6}$;

c) mercado de consumo: a consagração e circulação de imagens de "cidades-modelo" tende a agilizar os fluxos de consumo interno (de espaços "renovados" e de mercadorias) e externo (visitantes, consumidores de serviços especializados);

d) mercado do turismo: tem fortes imbricações com o mercado de cidades e, apoiado nesta relação, constrói suas segmentações e grupos-alvo no mercado, como o turismo urbano (com o consumo dos espaços modernizados), o turismo de negócios, o turismo cultural, o turismo de compras, de jovens ou de terceira idade;

e) mercado das chamadas "boas práticas": as agências multilaterais, sob manifestos objetivos técnicos, têm implícitos interesses políticoideológicos na promoção e difusão internacional de imagens de "cidades-modelo". Mediante a legitimação de "administrações urbanas competentes", "gestões competitivas" ou "planejamento urbano estratégico", as agências perseguem a reformatação do campo da administração pública e do Estado;

f) mercado de consultoria em planejamento e políticas públicas: atores locais, como prefeitos, lideranças ou experts internacionais em planejamento, constroem seus projetos políticos através da projeção e reconhecimento de sua atuação que, referida à escala do "local" necessita, entretanto, de legitimação em simultâneas escalas. As estratégias territoriais para exportar know how, por parte de governos locais e de consultores identificados com certas "experiências de sucesso" constroemse no campo simbólico, onde o que está em jogo é o poder propriamente político.

\section{AS LEITURAS DA CIDADE NUM CAMPO DE LUTA SIMBÓLICA}

O tema das leituras da cidade é de interesse em nossa abordagem do campo simbólico, onde

\footnotetext{
6 Exemplares, neste caso, são as grandes operações imobiliárias de Barcelona no período olímpico (1986-1992) e pósolímpico (1992 até o presente), em sua maioria, frutos de capitais externos, dos EUA e da Comunidade Européia .
}

se trava a luta política pela imposição, mediada sempre por conflitos e tentativas de construção de hegemonia, de uma leitura frente às muitas outras que estão em permanente disputa neste campo. Pensamos que essa luta simbólica possa se tratar de um dos processos políticos relevantes na compreensão daqueles mobilizados para a reconstrução de lugares, em relação dialética com os processos materiais de modernização urbana.

A relevância conferida ao tema está centrada no resgate dessa relação dialética. As lutas simbólicas não são mera expressão das relações de poder; elas atuam sobre o campo das práticas, elas reelaboram as práticas. Por seu lado, as práticas materiais ligadas à modernização dos espaços da cidade não se impõem facilmente. Pelo contrário, a legitimação dos projetos associados à modernização depende de estratégias discursivas e retóricas que parecem centrais. Desse modo, desconstruir leituras e discursos do espaço é interpelar seu léxico, seu padrão argumentativo.

Se ler a cidade significa ter uma representação de cidade, construir uma imagem de cidade significa também compreender e interpretar e, sobretudo, sintetizar, dada a complexidade do fenômeno observado. Porém, "leituras", no plural, implicam que a cidade pode ser representada, ou melhor, imaginada, a partir de diversos olhares. Não há uma única leitura possível. O que se vê depende de onde se olha e para onde se olha (RIBEIRO, 1999), e a análise deve identificar de quem são esses olhares ou quem realiza essas leituras.

As imagens-síntese oficiais, aquelas que se impõem como dominantes em cada cidade onde opera um projeto de modernização urbana definido e explicitado ${ }^{7}$, não deixam margem para dúvidas ou interpretações diversas sobre a informação que veiculam; não oferecem alternativas à sua decodificação. Organizam, a seu modo, a cidade, tornando-a simbolicamente eficiente, uma espécie de publicidade que concretiza o modo de reconhecê-la e avaliá-la. Leituras oficiais da cidade, que configuram imagens, costumam ser mostradas com aparência de objetividade, apresentando fatos sociais como inquestionáveis. Entretanto, são uma das linguagens do poder, convenção social e

\footnotetext{
7 Referimo-nos aos casos paradigmáticos, como o de Barcelona a partir do ano 1986, quando a cidade foi designada para sediar os Jogos Olímpicos de 1992; ou o caso de Curitiba, Brasil, com a modernização urbana iniciada na década de 70 .
} 
política questionável (DUNCAN \& LEY, 1993; MASSEY, 1993). Seu aparente realismo é, em essência, ideológico, pois passa como natural aquilo que é um fato cultural.

Como referências para a ação, as representações constroem-se a partir de uma dada posição social e orientam-se a determinados objetivos. Aparentes noções "neutras" escondem abordagens seletivas do real, assim como a atribuição ou destituição de sentido aos lugares (NOVAIS, 1999). Efetivamente, não existe um mundo neutro, visível, unívoco. Cada representação é uma verdade parcial, construída a partir de um "conjunto coerente de valores e orientações". Essa espécie de matriz que condiciona as representações está expressa na noção de habitus desenvolvida por Bourdieu (1999, p. 191). Mais que uma noção, trata-se de uma orientação metodológica que colabora no sentido de transcender a mitologia da mimese, pois permite a percepção de que o que é visto através das imagens não é uma realidade dada, objetiva, mas um conjunto de informações parciais, construídas a partir de uma determinada perspectiva, através de representações.

Neste ponto, parece central recuperar a reflexão lefebvriana acerca da produção do espaço: é necessário entender não apenas como os lugares adquirem qualidades materiais, mas também como adquirem valor simbólico através de atividades de representação. As representações influenciam avaliações e rankings de lugares e determinam parte considerável das escolhas locacionais. Veja-se, por exemplo, a transcendência que foi dada pelos veículos oficiais e pela mídia local em Curitiba à pesquisa divulgada pela revista Exame, sobre as "Dez melhores cidades para se fazer negócios" (2000), na qual Curitiba aparece em primeiro lugar, dando lugar à produção e veiculação de mais uma de suas imagens-síntese, "Curitiba, a melhor cidade para os negócios" (SÁNCHEZ, 2001).

Nas palavras de Harvey, "as possibilidades político-econômicas da reconstrução de lugares estão coloridas pela maneira evaluativa da representação dos lugares" (HARVEY, 1993, p. 22). Materialidade, representação e imaginação não são mundos separados. Nessa recusa à segmentação do conhecimento do espaço reside a força da construção de Lefebvre (1998). Como opção metodológica, evidencia as imbricações desses três domínios na produção do espaço, em processos de mútua transformação.
Há um complexo intercâmbio entre a transformação material e o simbolismo cultural, entre a reestruturação de lugares e a construção de identidades. Desse modo, a cultura é o meio que relaciona a textura da paisagem ao texto social. Como afirma Novais $(1999$, p. 2), o caráter dialético do processo de produção do espaço está dado pela imbricação do real com suas representações. As representações que os sujeitos têm do real influem na construção da realidade ao mesmo tempo que as práticas materiais são a base para novas representações do real.

As representações são também carregadas de intencionalidade: visam à produção de efeitos na realidade social. Assim, a construção de imagens opera necessariamente com sínteses, seletivas e parciais, que dão relevância a alguns aspectos e omitem outros, respondendo ao universo especial de interesses dos sujeitos que a constroem e aos objetivos que se pretendem.

Sujeitos, instituições, práticas e produtos circulam no âmbito de um "mercado material" e de um "mercado simbólico", de modo relacionado (BOURDIEU, 1999; LEFEBVRE, 1998, p. 86). Efetivamente, a produção, circulação e troca de bens materiais é diferente mas não separada da produção, circulação e troca de signos, linguagens e discursos (LEFEVRE, 1998, p. 100). Ao produzir um objeto material na cidade, uma praça, um monumento, um edifício, produz-se também a maneira como será consumido, através das práticas ideológicas que produzem o objeto sob a forma de discurso e imagem. Assim, a reelaboração simbólica que um discurso efetiva é parte integral da realidade social e, por essa razão, tal realidade é também constituída ou determinada pela própria atividade de simbolização.

O poder das representações está em sua presença material, literalmente solidificada na arquitetura e no urbanismo. As geografias da chamada renovação urbana são geradas por processos materiais mas também simbólicos, cujos idealizadores, planejadores e profissionais do marketing, codificam as formas construídas em códigos de consumo para receptores que irão reinterpretá-los.

Se há muitas possíveis leituras da cidade, isso implica que pode haver e que, de fato, exista disputa. A representação da cidade é um objeto cobiçado e disputado. Afinal, como nos diz RIBEIRO (1999), "representar a totalidade, o todo social, implica poder: implica construção de hegemonia, 
capacidade de convencimento, criação de consenso". Nesse sentido é que atribuímos alta relevância à reflexão sobre comunicação e informação, pois as imagens produzidas, tornadas dominantes, são territórios de investimentos simbólicos que necessitam ser permanentemente disputados na conquista e reprodução do consenso e na atração de novos investimentos.

Essa luta pela hegemonia do chamado "discurso forte" (BOURDIEU, 1998, p. 136), enquanto interpretação da realidade e legitimação dos projetos de futuro, está associada à elaboração de imagens, enquanto sínteses discursivas: um campo de disputas ampliadas visando, ao mesmo tempo, à conquista e à reprodução do poder político e econômico.

A mídia, em sua relação com os governos e coalizões dominantes, é um ator importante no cenário cultural e político atual nas cidades. Tem um papel importante nos processos que acompanham a renovação urbana, que interage e interfere no curso dos acontecimentos através de imagens publicitárias, mobilizações e campanhas sociais. Exerce um verdadeiro fascínio sobre a sociedade civil e política, e tem força de pressão na elaboração de imagens coletivas que possam ser absorvidas nas representações de indivíduos e grupos. Tem também poder para construir ou destruir a identidade de atores individuais ou coletivos.

Em seu papel de mediadora entre os cidadãos e a cidade, a mídia é estratégica para os governos locais, pois realiza a espetacularização da cidade e molda as representações acerca de sua transformação. Ela produz signos de bem-estar e satisfação no consumo dos espaços de lazer, cria comportamentos e estilos de vida e promove a valorização de lugares, bem como os usos considerados "adequados". Em outras palavras, celebra os novos lugares transformando-os em espetáculo. O caso de Curitiba é paradigmático na simbiose entre governo e mídia, com a promoção orquestrada de fragmentos renovados do espaço da cidade junto à difusão dos usos sociais considerados adequados, de acordo com o que se poderia chamar de ethos do "curitibano típico": na leitura oficial da cidade, aquele cidadão que freqüenta parques, bosques ou os edifícios culturais e de lazer mais emblemáticos da modernização urbana da última década, como a Rua 24 Horas, as Ruas da Cidadania, o Jardim
Botânico ou o Memorial da Cidade (SÁNCHEZ, 1997).

\section{RENOVAÇÃO URBANA, CULTURA E ECONOMIA}

As considerações da sessão anterior permitem evidenciar que as políticas culturais de lugares vêm sendo cada vez mais alinhadas às políticas econômicas. É nesse sentido que pensamos, com alguns autores, que o poder das representações é ferozmente disputado e tão fundamental aos projetos de reestruturação urbana ou aos chamados processos de "re-invenção de lugares" quanto tijolos e concreto (DUNCAN \& LEY, 1993, p. 27; HARVEY, 1993, p. 23, WARD, 1998, p. 233).

Ousamos dizer que, nos casos das cidades de Curitiba e Barcelona aqui referidos, a mobilização política para a reestruturação das cidades deve-se tanto a atividades no campo simbólico quanto a atividades materiais. $\mathrm{O}$ sentido de pertencimento ao lugar, estimulado pelos "projetos de cidade" em curso, tem significados políticos - evidência de que o poder político pode ser mobilizado e exercido através de atividades de modernização urbana tanto nas mentes quanto no chão.

Verificamos, nesses casos, que as lideranças políticas protagonistas dos projetos modernizadores investem, particularmente, em construções discursivas de lealdades afetivas. Em virtude desse investimento no lugar e da associação, trabalhada nos planos simbólico e afetivo, entre a liderança política, os cidadãos e o lugar, parece haver um significativo ganho de poder para tais lideranças. De fato, pensamos, na direção de Massey (1999, p. 292), que o poder social é necessariamente espacializado; as várias formas de poder social são constituídas espacialmente. Nesse sentido, é importante lembrar, para o caso de Curitiba, as representações recorrentes em campanhas eleitorais, desde os anos 80, que procuravam contrapor os candidatos como "o Prefeito da Cidade" (Jaime Lerner) ao "Prefeito de um partido" (Roberto Requião), procurando construir a superioridade do primeiro frente ao segundo.

Com significativa recorrência nos processos locais, o primeiro passo para a auto-definição é a definição do "outro" de modo excludente e estereotipado. A desqualificação do "outro", sejam cidades ou regiões, parece ser uma ferramenta para a qualificação do "nós", para a construção do sentido de pertencimento. O processo de 
representar a diferença, o outro, é uma prática política e a desqualificação de outros lugares gera poder para os sujeitos do próprio lugar.

Porém, essa oposição binária entre nós e os outros, se por um lado reforça e define a identidade do lugar, por outro lado, simultaneamente, ordena a diferença complexa através de uma simplificação mais facilmente apropriada. As múltiplas identidades e diferentes formas de vida social, que coexistem na cidade, são simplificadas, depuradas numa única identidade que se pretende sintética.

A questão das leituras da cidade parece ter, de fato, implicações no alargamento do campo da política em sua relação com o espaço. Pensamos com Massey (idem, p. 281) que uma das características cruciais do "espacial" é a possibilidade de existência de multiplicidade de leituras e narrativas. Espaço, no argumento desse autor, é a esfera do encontro, ou não, de múltiplas trajetórias, a esfera onde elas coexistem, afetam umas às outras, entram em conflito. É a esfera tanto de sua independência, coexistência, quanto de sua inter-relação. Assim, a diversidade de leituras da cidade não corresponde somente à diversidade de representações mas também à existência mesma de diferentes realidades sociais no espaço.

Segundo essa interpretação, as imagenssíntese da cidade, aquelas às quais se atribui o poder de falar por ela, constituem-se na negação da possibilidade de existência de outras imagens e de outras leituras. Ao operar com imagens-síntese retira-se da cidade o que lhe é politicamente essencial: a multiplicidade enquanto coexistência e possibilidade de conflito, de exercício da política. Se espaço e multiplicidade constituem-se mutuamente, uma de suas expressões sociais pode ser a diversidade de leituras sobre a cidade, com potenciais desdobramentos em diversidade de projetos e abertura do futuro.

A leitura da cidade e sua disputa expressam a política, são fatos essencialmente políticos. As identidades são relacionalmente construídas como parte do processo político mediante relações de poder, mapas do poder, geometrias do poder. Esse reconhecimento pode levar à renegociação dessas identidades, pois reformular o modo através do qual se representa o espaço é também uma ação política.
Sínteses e imagens fazem parte da retórica oficial que acompanha os processos de reestruturação. Subjacente a essas sínteses encontra-se a proposta de uma ordem urbana que pretende fazer impensáveis e impossíveis outras formas de viver na metrópole, conflitivas com os parâmetros da cidade-mercadoria e da cidadeempresa que se busca consolidar. Tudo aquilo que não adere a essa dinâmica é interpretado como ingovernabilidade, como perturbação da ordem urbana que deve ser desalojada do panorama da modernização.

Ações para potencializar o consenso e esvaziar o dissenso são desenvolvidas para assegurar a viabilidade do projeto modernizador. A reestruturação urbana só é possível quando acompanhada de uma reestabilização do governo do urbano: reestruturação e governabilidade do social são as duas caras da moeda da ordem urbana. As tecnologias do controle, aliadas aos circuitos da comunicação social, emanam um fluxo ininterrupto e constantemente atualizado, de informações que ordenam a vida social.

De fato, a potenciação dos processos de informação tem sido transformada em peça-chave dos governos das cidades e a informação midiática, através de múltiplas modalidades, tem sido escolhida como forma privilegiada da relação entre a administração pública e os cidadãos. Esses processos técnicos de informação configuram um "circuito propriamente político entre dominantes e dominados", através dos diversos "aparelhos de produção simbólica” (BOURDIEU, 1999).

Entretanto, a cidade nunca está totalmente tomada pelo poder do Estado midiático, pois há sempre espaço para possíveis ações. Processos constitutivos de sujeitos coletivos expressam maneiras de viver e reapropriações da cidade afastadas das previsões da ordem urbana promovida pela imagem oficial. Os sujeitos sociais, mediante esses diferentes modos de participação, lêem a cidade de modo diferente, fazem usos divergentes do território. Reformulam o modo através do qual se imagina e se representa o espaço e a espacialidade, reformulação que está associada, efetivamente, a uma ação política.

Os lugares são repletos de diferenças internas e conflitos, que podem ser expressos em leituras dissonantes em disputa de espaço político. Se nas cidades há múltiplas identidades que podem ser "recurso de riqueza ou fonte de conflito" 
(MASSEY, 1993, p. 65) é necessário, portanto, questionar a idéia da "identidade do lugar" como se fosse única, ou da "imagem-síntese do lugar", idéias-força do discurso urbano dominante que se tornam armadilhas e fetiches. Elas inevitavelmente carregam uma leitura feiticizada e reducionista das relações sociais, pois, nas operações de síntese, prevalecem aqueles traços identitários instrumentais às relações dominantes de poder.

A hegemonia é construída ao evocar uma identidade territorial homogênea, que precisa de proteção contra o diferente-externo. Essa identidade unificadora em torno ao lugar é evocada pela intelligentsia urbana vinculada ao novo projeto modernizador. Está presente em obras consideradas referenciais para a difusão do modelo de reestruturação urbana contemporâneo como analisado, por exemplo, em Borja e Castells (1997) ou Borja (1995). Esses autores assumem uma perspectiva teórica, com evidentes desdobramentos políticos e culturais, que valoriza a construção do sentido de lugar associada à construção de uma identidade unificadora. A questão da identidade consensuada é apresentada como condição de sobrevivência e êxito da cidade face à globalização. Segundo os mesmos autores, se não for vigorosamente perseguida essa identidade "de todos" junto a uma atitude competitiva agressiva, será difícil desviar-se de um cenário de futuro apocalíptico.

Nossa argumentação é que a ordem necessária para impor os projetos de modernização constróise em larga medida mediante o controle sobre a produção simbólica, sobre a produção das representações espaciais. Os discursos reguladores contidos nas novas políticas e interpretações sobre a cidade e o mundo permeiam os espaços mentais e são, portanto, parte das representações do poder, da ideologia e do controle.

Nesse sentido, representar o espaço é, portanto, um ato de poder simbólico. Como observa Novais (1999, p. 2), o espaço está em disputa, inclusive no nível das representações. Trata-se de uma luta pelas representações dominantes, uma disputa para impor visões de mundo manipulando imagens do real.

Entendimentos particulares de certos conceitos e noções tornam-se apropriados em momentos específicos do espaço-tempo e a partir de perspectivas políticas particulares. Nesses momentos, as formas de representar o espaço são ativamente mobilizadas. Diante dessa mobilização, há também maneiras de defender formas particulares de pensar e entender o espaço, como recusa às armadilhas de formulações hegemônicas prévias, abrindo terreno para novas questões que politicamente precisam ser apresentadas. Segundo Massey, essa recusa às formas dominantes de representar e pensar o espaço estaria contribuindo também para construções mais abertas de futuro (MASSEY, 1999, p. 285).

\section{UMA NOVA LINGUAGEM SOBRE AS CIDADES: ATORES E GEOGRAFIA DA DIFUSÃO}

A difusão, na escala mundial, de representações e leituras sobre as cidades, sobre a crise e sobre os projetos de reestruturação, encontra-se associada à difusão de uma nova linguagem planetária, "produto de um imperialismo propriamente simbólico" (BOURDIEU \& WACQUANT, 2000). O chamado "imperialismo simbólico" é, para esses autores, uma violência cultural que se apóia no alargamento e agilização das relações de comunicação. Uma das expressões desse fenômeno é que ele universaliza os particularismos, as representações particulares sobre as relações entre as cidades e o mundo, e as faz serem reconhecidas como universais.

Pensamos que o city marketing e a imposição de imagens urbanas tornadas dominantes contribui para o exercício da violência, especialmente em sua forma simbólica, pelas vias da comunicação e do conhecimento, violência nem sempre percebida por suas próprias vítimas.

Com efeito, a discussão acerca dos processos de reestruturação urbana e da "necessidade de inserção competitiva das cidades" vem acompanhada por uma significativa mudança na linguagem relativa ao planejamento e à gestão. Nessa sentido, como nota Oliveira (1999, p. 141), "as metáforas e analogias próprias do novo discurso se destacam pela grande potência que têm mostrado no sentido de imprimir novas direções ao pensamento e às experiências na gestão". Cidade-empresa, cidademercadoria são algumas das analogias que emergem e se afirmam nesse novo repertório, com perceptíveis influências nas representações sociais e nas relações de poder na cidade. Metáforas constitutivas do novo discurso sobre o urbano na virada de século tornam o city marketing um imperativo, um instrumento de difusão de determinadas representações que estariam sendo afirmadas. 
Outro aspecto que evidencia a manipulação simbólica operada pela nova linguagem é a subordinação do debate ao chamado desempenho eficaz da administração pública, em termos de efetiva integração competitiva. Essa subordinação "responde a uma versão tecnocrática da sociedade que esvazia a dimensão política do Estado, subsumindo as demandas sociais na esfera técnica" (idem, p. 150).

A nova retórica associada ao projeto dominante de modernização urbana, que tece as figuras de linguagem em discursos e imagens da reestruturação, entretece também interpretações e leituras do mundo que lhe dão sustentação. A reestruturação das cidades é apresentada como um imperativo da reestruturação produtiva no "mundo-globalizado". Para tratar as questões das cidades através do discurso supostamente mais renovador, aquele capaz de ter maior alcance, há também uma disputa pelo sentido do contexto, pelas representações do mundo que se pretendem tornar categorias de análise do mundo. Desse modo, as metáforas e analogias que ordenam o discurso da cidade têm imbricações com as metáforas e analogias que ordenam determinada visão de mundo: "é preciso afirmar a síntese 'mundo-globalizado' para afirmar a metáfora "cidade-empresa"' (idem, p. 154).

Metáforas e figuras de linguagem, com o tempo, podem ser naturalizadas e incorporadas como moeda corrente na interpretação das questões relativas às cidades. Entretanto, a pertinência da metáfora é construída socialmente, inserida em visões de mundo que estão em permanente disputa.

O sentido figurativo pode transformar-se em literal no curso da disputa para tornar dominante determinada visão de mundo. Como observa Oliveira, "literal" e "figurado" não são esferas distintas, mas os limites de um continuum metafórico em que "a linguagem começa como metáfora e apenas depois de longo uso endurece ou congela como literalidade". Assim, o emprego recorrente da metáfora "cidade-empresa" poderia conduzir, com o tempo, à transformação da metáfora na representação social dominante de cidade, não mais "como se fosse" uma empresa mas já como "um tipo singular" de empresa (ibidem).

A construção de uma ponte cognitiva entre cidade e empresa ou entre cidade e mercadoria estabelece relações entre atributos de uma e de outra que impulsionam uma nova maneira de representar mas também de administrar a cidade.
Os novos significados transformam-se em vetores pois favorecem certas práticas sociais e políticas em detrimento de outras. A manipulação simbólica operada pela linguagem celebra determinadas palavras-chave que reafirmam, pela repetição exaustiva, as receitas contemporâneas para as cidades.

Nessa luta simbólica, não parece estar em jogo a compreensão da complexidade da cidade, visto que, segundo nos lembra Lefebvre (1998, p. 98), a terminologia figurativa utilizada é muito mais metafórica do que propriamente conceitual. Trabalhar com as diferentes leituras do espaço da cidade exige, metodologicamente, a distinção clara entre pensamento e discurso sobre o espaço (palavras, imagens, símbolos) e pensamento adequado ao entendimento do espaço (fundado em conceitos) (idem, p. 104). A metaforização tem instrumentalidade, eficácia para responder aos quesitos de uma nova ordem, mas não propriamente potencialidade para o entendimento do espaço.

As noções que fundamentam os atuais projetos de reestruturação urbana servem de referencial para compreender o mundo globalizado e elaborar ações para nele vencer. Estão sujeitas a manipulações e a tentativas de imposição de visões de mundo. Podem ser interpretadas como "formas programadas - ideológicas - de conhecer e agir no mundo" (NOVAIS, 1999, p. 14).

As idéias mais recorrentes sobre a globalização têm em comum a ênfase no capital e na empresa como motores do processo ou seja, o mundo global é aquele "dominado pela rede de conexões - de idéias, dinheiro, comunicação - que são centradas no mundo desenvolvido". Entretanto, cada globalização, segundo a perspectiva a partir da qual seja lida, constrói um mundo diferente a partir de certas idéias-força (idem, p. 10).

A propósito da possibilidade de encontrar diversos mundos, e diversas visões de mundo, que escapem à crença de que o mundo apresentado é o verdadeiro, parece pertinente a orientação de Santos: "[...] devemos considerar a existência de pelo menos três mundos num só. O primeiro seria o mundo tal como nos fazem vê-lo: a globalização como fábula; o segundo seria o mundo tal como ele é: a globalização como perversidade; e o terceiro, o mundo como ele pode ser: uma outra globalização" (SANTOS, 2000, p. 18).

A retórica ligada à globalização responde a uma 
ideologia que, decididamente, comparece para construí-la, com um notável papel na produção, disseminação, reprodução e manutenção da globalização atual (BOURDIEU, 1998; SANTOS, 2000). Entretanto, a racionalidade dominante, que apresenta a globalização como fato inexorável, tem seus limites, que devem ser avaliados e explicitados, para resgatar a relevância e potencialidades da política bem como as condições para a mudança.

Se é notável, no discurso dominante sobre o urbano, a emergência de lugares-comuns planetarizados, mundializados, eles parecem referir-se a condições históricas e políticas particulares, que propiciaram a difusão de uma determinada leitura, tornada hegemônica, tacitamente constituída em modelo e medida de todas as coisas. Impondo ao mundo todo determinadas categorias de percepção e representação, os atores dominantes na produção de modelos e políticas urbanas refazem o mundo à sua imagem, com uma colonização mental que se opera através da difusão dessas categorias e representações, produzidas e reproduzidas num processo de luta simbólica.

Em determinadas circunstâncias, as representações sobre as cidades podem ser poderosas em suas consequiências locais, regionais, nacionais e internacionais. Podem ter desdobramentos geopolíticos e econômicos que repercutem em variadas e simultâneas escalas. Devido a essa dimensão, não costumam ser pautadas pelos parâmetros e objetivos definidos apenas pelas autoridades dos governos municipais. Para a sua elaboração acurada comparecem necessariamente saberes de experts provenientes de campos cada vez mais especializados. Publicitários, consultores em marketing, produtores culturais, conselheiros em comunicação e pesquisadores de mercado são os agentes exemplares que emergem como figuras centrais associadas à gestão empresarial das cidades. Têm como missão dar forma mercadológica aos projetos políticos das coalizões com interesses localizados.

As representações e discursos devem, também, o essencial de sua força de convicção ao prestígio dos sujeitos e instituições a partir dos quais emanam e circulam como fluxos. São apresentados em toda parte, simultaneamente, a partir das instâncias pretensamente neutras do pensamento neutro que são os grandes organismos internacionais como o Banco Mundial, a Comissão Européia, a ONU e as grandes mídias, distribuidoras desta "língua franca passe-partout" (BOURDIEU \& WACQUANT, 2000).

Diversos níveis institucionais e diferentes corpos de agentes altamente especializados, públicos e privados, respondem a funções determinadas no processo de produção simbólica. As atividades no campo simbólico devem ser capazes de assegurar, mediante técnicas e métodos articulados, a difusão de discursos e imagens que façam valer os interesses dominantes e que construam a adesão social em torno de determinados projetos. O que está em jogo no campo simbólico é o poder propriamente político. Linguagens especiais encobrem as condições objetivas e as bases materiais em que tal poder se funda.

Grandes empresas de publicidade e marketing e os principais veículos da mídia dominam os conteúdos e sua divulgação, daí porquê os principais agentes a elas relacionados concentram imenso poder, que não é simplesmente o poder do dinheiro, mas o poder que a riqueza exerce sobre os espíritos, sobre as mentes. É algo que amplia a definição dos campos de poder, diferentemente do poder político ou econômico.

A luta simbólica é travada também pelo reconhecimento de autoridade para falar sobre a cidade. No discurso da "cidade-empresa" e da "gestão empresarial da cidade", há uma construção mitificada da figura do líder carismático, do administrador erudito, da liderança política enaltecida sobretudo pela competência técnica capaz de situálo acima da política, requisitos tidos como indispensáveis do "Prefeito empreendedor" ou dos agentes portadores da missão de desencadear planos e projetos estratégicos associados à reestruturação urbana.

A apresentação do perfil técnico ou erudito de determinada liderança qualifica-a como portadora de aparente imparcialidade e conhecimento científico sobre as questões urbanas. Trata-se da manipulação política do denominado "discurso competente", discurso com aparência científica que permite a dissimulação de práticas de subordinação. São exemplares as representações, já mitológicas, que cercam as figuras dos exPrefeitos, ambos por longos períodos, Pasqual Maragall (Barcelona) e Jaime Lerner (Curitiba).

A leitura técnico-material das cidades não está, portanto, fora da luta das representações e, na forma de um "discurso competente", pode partici- 
par da difusão de um conjunto de idéias convenientes e interesses particulares. As noções e representações a respeito da cidade impõem-se pela autoridade de quem as divulga e pela repetição incessante de sua pseudo-verdade, a fim de garantir sua visibilidade e aceitação cultural (NOVAIS, 1999, p. 10).

Parece claro que as representações do espaço relacionam-se com as condições políticas, culturais e materiais dominantes das diferentes épocas. Quanto à época presente, nossa análise das políticas de promoção das cidades, ou, como preferem alguns autores, da "re-invenção das cidades" (WARD, 1998), parece indicar a emergência de um conjunto de representações que desenham uma cidade ideal, fruto de uma competição imagética, de uma luta simbólica que procura dotar esta cidade ideal das quantidades apropriadas de valores hegemônicos. Efetivamente, há suficientes indicadores da existência de uma rede global onde operam fluxos informacionais ligados a representações de uma urbanidademodelo, ao nosso ver, descolada e imposta à urbanidade social complexa. Nessa esfera da circulação simbólica, discursos, imagens e políticas de city marketing acompanham e alimentam processos de reestruturação produtiva e de atração de capitais internacionais.

\section{O PATRIOTISMO DE CIDADE}

A participação dos cidadãos, o sentido de pertencimento à cidade, a adesão aos novos projetos ou serviços oferecidos, o elevado grau de aceitação e aprovação pública dos "projetos de cidade" e, principalmente, a aparente unanimidade que alguns projetos têm alcançado são elementos reiteradamente apresentados pelos governos municipais através das imagens hegemônicas de Barcelona e Curitiba, para mostrar o êxito de seus projetos.

Entretanto, torna-se necessário deter-se na natureza dessa participação: trata-se de uma participação efetiva ou representada, passiva ou ativa, legitimadora ou transformadora dos projetos oficiais? Essas perguntas parecem centrais para aqueles que reivindicam a necessidade de decodificar os projetos de renovação urbana. Torna-se necessário deter-se na relação entre projeto político de cidade e criação de patriotismo urbano, tratados nesta seção através desses dois casos específicos.

Ao interpretar a produção de imagens e as políticas de city marketing como instrumentos de legitimação dos projetos de modernização e de promoção da coesão social, destaca-se que o poder político através da mídia parece exercer um crescente domínio sobre a vida coletiva nas cidades. Os projetos de cidade construídos e afirmados também enquanto projetos de comunicação, por serem de mão única, parecem comprometer o jogo democrático mais amplo, aquele que se estabelece pelo confronto de atores e projetos políticos na e pela cidade.

A publicidade em televisão, rádio, imprensa e demais meios de comunicação e informação que, nos casos analisados, têm sido intensamente utilizados como veículos construtores de determinadas leituras da cidade, intervêm decisivamente na criação de valores culturais e de representações sociais que, por sua vez, promovem determinados comportamentos e formas de utilização dos espaços públicos (SÁNCHEZ, 1997, p. 66-68). A ilusão de objetividade, a aparência de ordem "natural", permitem a aceitação passiva de valores culturais, políticos e morais dos grupos ligados ao projeto político dominante frente aos demais grupos subordinados.

Ao tratar da renovação urbana de Barcelona no período olímpico e pós-olímpico, P. López Sánchez (1993, p. 103) refere-se à "fabricação de uma cidadania" ajustada ao projeto, como um de seus principais pilares políticos, visando a garantir a ordem social na cidade. Para ele, o estímulo a essa condição cidadã fabricada é motor do projeto, iniciado em $1986^{8}$, da "Barcelona competitiva".

Desse modo, a coalizão dominante procura legitimar o projeto de cidade na medida em que "faz cidade" 9 e, ao mesmo tempo, fabrica cidadãos à sua medida. Essa representação da cidade e da vida social está presente nos documentos oficiais que apresentam como "princípio básico" da política e da ação na cidade a "Generación de un patriotismo de la ciudad que permita a sus líderes, actores y conjunto de la ciudadanía asumir con orgullo su pasado y su futuro, y especialmente su actividad presente [...]" (BORJA, 1990, p. 62).

Nesse documento, lado a lado com a geração de patriotismo de cidade, está a "definição de um

\footnotetext{
8 Ano da denominação de Barcelona como cidade anfitriã para as Olimpíadas de 1992.

9 A expressão “fazer cidade" se impôs na Espanha e na América Latina como uma das representações mais fortes associadas ao urbanismo de resultados, à demonstração dos espaços de modernização produzidos.
} 
projeto de cidade que mobilize recursos, energias e ilusões" (ibidem). Projeto de renovação e patriotismo de cidade estão encadeados. Na configuração do espaço político da metrópole em renovação, é evidente o caráter regulador do governo da cidade: sob o aspecto ideológico, através do reforço ao patriotismo de cidade; sob o aspecto prático, através da implementação do projeto de cidade e da instrumentalidade dos espaços modernizados; sob o aspecto tático-estratégico, através da subordinação do projeto aos objetivos políticos de reposicionamento territorial de Barcelona no sistema urbano europeu.

Desse ponto de vista, a comunicação social tem sido um dos elementos centrais dos projetos de reestruturação urbana tanto em Barcelona quanto em Curitiba. Ela tem desempenhado um papel fundamental na busca do necessário consenso social ao redor dos projetos, melhorando sua efetividade, sobretudo se for considerado que a implementação dos mesmos acarretou períodos de mudanças profundas e muito rápidas.

Assim, a participação da população, estimulada através da mídia e do conjunto de campanhas de comunicação, é uma participação vinculada à adesão a programas e políticas oficiais, uma participação legitimadora e não transformadora dessas políticas. Essa idéia de participação é coincidente com aquela que impera no governo municipal de Curitiba, por exemplo nas campanhas de educação para o trânsito ou nas campanhas de reciclagem de lixo. A construção de um projeto de cidade respaldado por um aparente consenso encobre práticas autoritárias e tecnocráticas nas definições das políticas, com escassas possibilidades de influência da sociedade civil.

\section{O PAPEL DAS CAMADAS MÉDIAS NA DEFESA DA CIDADE-PÁTRIA}

As campanhas oficiais que acompanham as políticas destacam, com ênfase, a vontade de envolver os cidadãos nos projetos de renovação urbana. De fato, em ambas as cidades, os grupos políticos que vêm detendo o poder nos governos municipais há décadas ${ }^{10}$ criaram para a maioria da população um sentimento de orgulho e de pertencimento à cidade. Esse sentimento gera, entretanto, mais do que uma participação ativa,

10 Em Barcelona, desde o ano de 1979; em Curitiba, desde 1971, com apenas um período de descontinuidade política nos anos 80 (1983-1989). uma participação contemplativa da cidade. Com efeito, cabe pensar que a assistência ao espetáculo cria uma forte ilusão de participação.

Observa-se que os cidadãos sentem-se partícipes e beneficiados por essas políticas; não obstante isso, assistem a um espetáculo de transformações para o qual são convidados para um lugar aparentemente preferencial, mas que resulta ser apenas uma parte do cenário. Os cidadãos contemplam a cidade modernizada como os "figurantes de um grande anúncio de griffe urbanística" (SÁNCHEZ, 1997, p. 44).

Efetivamente, muitos investimentos, públicos e privados, concentrados territorial e socialmente, que poderiam gerar conflitos pela distribuição de recursos, são apresentadas como, "a longo prazo, bons para todos". A identificação entre os cidadãos e a "imagem de marca" de sua cidade têm-nos levado a aceitar com maior facilidade os transtornos ou sacrifícios em sua vida quotidiana, apesar de que em muitos casos tenha sido possível identificar os significativos custos sociais derivados das remodelações urbanas ${ }^{11}$, caracterizando a seletividade da modernização. Por trás da aparente unanimidade em torno dos benefícios da modernização, é possível encontrar expressões reveladoras das outras faces da mesma, como indicam estes trechos: "En Barcelona se han reducido las desigualdades, pero no por un proceso de movilidad ascendiente de las clases populares, sino porque buena parte de éstas está siendo, poco a poco, sustituida o expulsada por quienes tienen mayor poder adquisitivo. Barcelona será cada día una ciudad más rica porque se debe contar con recursos para vivir en ella, y con una población más envejecida, ya que los que se tienen que marchar son los jóvenes" (FAVB, 1992, p. 60). "Durante estos años, la construcción de las grandes infra-estructuras viarias ha aumentado objetivamente la accesibilidad - en coche privado - de la periferia al centro de la ciudad. Desde luego, la atención y rigor para mejorar las condiciones de habitabilidad no han estado a la altura del resto de las obras realizadas durante la década pré-olímpica en Barcelona" (idem, p. 67).

\footnotetext{
11 Falamos, por exemplo, da renovação de bairros que está implicando a expulsão de parte de sua população original, ou do aumento do custo da moradia provocada por processos de repentina revalorização que conduzem a uma transformação substancial da composição social dos habitantes da cidade.
} 
De fato, junto aos que de uma ou outra maneira obtêm vantagens dos efeitos da renovação urbana e, portanto, estão interessados em promovê-la, há amplos setores da população que não participam diretamente dos benefícios mas que, mesmo assim, terão que assumir seus custos. Para eles, o acesso aos benefícios da modernização é possível apenas no plano do imaginário. Com a veiculação exacerbada dos hábitos da classe média, a virtualidade do usufruto constitui um elemento de fixação da linguagem mítica aparentemente tão relevante quanto o usufruto ou consumo efetivos.

A difusão de valores e modos de vida próprios das camadas médias contribui para a consolidação da representação da vida urbana construída com base na imagem de uma ordem urbana harmoniosa e sem conflito. A forte veiculação das imagenssíntese da cidade intensifica a idéia do socialmente pleno usufruto dos novos espaços - produtos da modernização - e implicitamente sugere a existência de uma vida de classe média para todos os habitantes.

De fato, estudos acerca do uso social dos espaços públicos de renovação em Curitiba mostram uma forte afluência das camadas médias e uma composição social bastante seletiva nos mesmos, particularmente nos novos espaços culturais (SÁNCHEZ, 1997). Freqüentemente, as formas de uso desses espaços podem ser lidas enquanto sínteses do novo padrão de vida coletiva veiculada pelo city marketing. Respondem a valores culturais fortemente associados ao estilo de vida das camadas médias. A capacidade de "capturar" esse setor da sociedade reside na evidente adequação entre os significados dos novos espaços e o conjunto de representações dos cidadãos - seus consumidores. O espaço é consumido como outro produto qualquer e para intensificar esse consumo os governos municipais, através do marketing, utilizam-se de mecanismos de sedução associados à oferta do produto-espaço.

Com efeito, as imagens dos novos espaços produzem maior ressonância junto àqueles aos quais implicitamente se dirigem. As camadas médias nelas identificam-se, refletem-se, o discurso projetase sobre o outro que lhe serve de espelho e identifica-se com ele. Há uma identificação mútua entre este projeto de cidade e as camadas médias, recentemente capturado pelo olhar da literatura, que espelha "o conservadorismo pós-moderno do cidadão curitibano": "Nesta cidade fortemente oficial o que não se integra pela mídia não se converte em notícia, não aparece e, portanto, não existe [...]. Vive-se a estreiteza do dia-a-dia, com a trivialidade de indivíduos podados em sua auto-afirmação” (TEZZA, 2001). “Às vezes penso que Curitiba é uma cidade exacerbadamente mental. Trazemos essa Curitiba entranhada na cabeça, tão ou mais real do que a feita de areia, pedra e cimento. É a essa Curitiba que pertencem os limites de nossa autofagia, de nossa frieza, de nossa soberba provinciana. O que está em curso aqui é a confirmação dos valores máximos da classe média brasileira. Assim, Curitiba atrai mais o igual do que o diferente, mais o conservador do que o ousado, mais o consumidor do que o criador" (DALA STELLA, 2000).

Esta identificação das camadas médias com o projeto de cidade mostra-se também clara em levantamentos qualitativos realizados em Barcelona. Um exemplo é “Barcelona a 100” (AROCA \& VILLALONGA, 1997), publicação resultante de cem entrevistas a profissionais de diferentes áreas com idades entre 30 e 40 anos, identificados, pelas autoras, como "protagonistas de uma nova geração, o futuro mais imediato desta Barcelona que experimentou uma revolução urbanística e que cresce tão vertiginosamente como eles" (idem, p. 7). Os gostos, expectativas e projetos das camadas médias, das quais esse grupo de profissionais parece representativo, têm uma sobreposição com aquelas representações que constroem as imagens oficiais, sendo pouco presentes imagens conflitantes, críticas ou divergentes.

As camadas médias procuram espetáculos e bons serviços buscando a constante elevação do nível de vida. Assim, nesses projetos de cidade, o consumo do espaço parece estar fortemente associado ao consumo da cultura e ao consumo acelerado de bens e serviços. Os cidadãos de classe média, no usufruto dos novos espaços, parecem encontrar-se a si mesmos; parecem dizer algo de si mesmos para si mesmos. Tanto no plano das práticas espaciais quanto no plano ideológico é esse setor da sociedade que, na reprodução cotidiana e silenciosa dos valores e representações dominantes, na defesa irredutível do projeto de cidade, encarna com mais força o conservadorismo e a despolitização produzidos pela cidade-pátria.

\section{A ENGENHARIA DO CONSENSO}

O notável grau de identificação do cidadão com 
sua cidade $^{12}$, sem dúvida um dos objetivos explícitos dos gestores de imagens, tem como conseqüência a imposição de barreiras ao exercício da participação crítica. Ainda mais, o modelo comunicacional adotado, os recursos de linguagem utilizados bem como o peso dos agentes econômicos envolvidos nos projetos de cidade distanciam os cidadãos da tarefa de elaboração do futuro coletivo.

De fato, as políticas de comunicação social têm o efeito de produzir na população a sensação de viver num meio privilegiado, o qual, levado ao seu limite, tem colocado de manifesto em alguns momentos um sentimento ufanista dos cidadãos com sua cidade. Em algumas ocasiões, essas demonstrações de exaltação ao lugar aparecem de modo bastante explícito, como num vídeo de promoção das transformações de Barcelona protagonizado por um casal de namorados - ela barcelonesa, ele estrangeiro, o qual, depois de passear pelas áreas renovadas da cidade, exclama: "Do you realize how lucky you are to live in Barcelona?"13 (Barcelona, una passió, 1992).

Essa hábil engenharia do consenso, tão cara às políticas urbanas de virada de século, está também presente como instrumento legitimador dos planos estratégicos de cidade. Com efeito, dentre os fatores apresentados para explicar o êxito dos planos em algumas cidades, Borja destaca: "acordo entre atores urbanos, públicos e privados" e "vontade conjunta e consenso entre os cidadãos para que a cidade desse um salto, tanto do ponto de vista físico como do econômico, social e cultural" (BORJA, 1996, p. 84).

Essa idéia do consenso-cidadão ou, em outras palavras, da sustentabilidade social do projeto, não tem apenas a função de ser um cimento social indispensável na escala local. Passa a ser também, no mercado externo, um elemento de medida da capacidade de atuação e do grau de confiança que merecem as elites locais para viabilizar futuros investimentos, ou seja, um elemento mais de atratividade locacional. Nesse sentido, a mídia incide, especialmente, através de notícias de oti-

\footnotetext{
12 Esta ampla identificação pode ser verificada em pesquisas de opinião, pesquisas de popularidade dos prefeitos ou mesmo, resultados de eleições municipais. Ver, a esse respeito Aroca e Villalonga (1997) e Sallas (1999).

13 "Você se dá conta da sorte que você tem por viver em Barcelona?"
}

mismo econômico, de harmonia social, de qualidade ambiental e de cooperação governamental com a iniciativa privada, sugerindo um entorno propício para os investimentos.

A necessidade de transmitir a existência de uma atmosfera propícia aos negócios fica bem explícita em Barcelona, onde o governo municipal publica uma revista, em catalão, espanhol e inglês, dirigida ao mundo empresarial internacional, com o significativo nome de Barcelona, buenas noticias, com a finalidade de dar conhecimento de fatos econômicos exclusivamente positivos, tais como empresas estrangeiras que investem em Barcelona, empresas barcelonesas que se implantam no exterior, novas infra-estruturas logísticas, melhorias urbanísticas ou resultados do ano turístico. Em orientação semelhante, Curitiba vem sendo divulgada como "a melhor cidade brasileira para se fazer negócios".

As diretrizes que norteiam a atuação municipal na área da comunicação seguem uma lógica essencialmente técnica, que se manifesta por uma concepção específica de participação. Ela tem, antes de mais nada, valor instrumental para o aperfeiçoamento dos projetos administrativos e é considerada imprescindível para a implementação eficaz dos mesmos, uma vez que cria uma certa pressão moral e ética para o cuidado com a cidade. A mobilização popular não se refere à tomada de decisões políticas; ela acontece apenas na fase de implementação dos projetos. A competência e eficiência do governo municipal, destacadas ad nauseum na comunicação oficial, servem para deslegitimar quaisquer outras formas de participação que verdadeiramente disputem espaço político. Assim, o cultivo ao patriotismo de cidade tem a sua contraface, que é o esvaziamento da política.

Tanto em Curitiba como em Barcelona opera um viés ideológico comum: trata-se do uso da emoção como instrumento político, dentro das estratégias de criação de identidade local (FREY, 1996, p. 123). A construção, mediante fortes aparatos de comunicação, de uma relação emotiva e afetiva entre a população, o governo municipal e a cidade parece central para explicar o êxito desses projetos políticos nos anos 90 . O reforço dessa relação emotiva procura assegurar a sustentação (passiva) da população para a política municipal, assim como a disposição da população em participar da implementação dos projetos da Prefeitura.

Aos habitantes da cidade-pátria, essa coleção 
de indivíduos que vivem juntos, porém isolados, receptores de notícias e anúncios em domicílio (uma vez que triunfa a forma cultural da "íconedependência") (JAMESON, 1995, p. 103), resultalhes difícil escapar à condição de espectadores e consumidores de imagens. Nesse sentido, como observa López Sánchez (1993), a mercantilização da cidade e sua linguagem promocional constrangem os terrenos de intervenção social nos espaços urbanos.

A política de comunicação social, além de instrumento para a renovação urbana, visa a construir uma ordem urbana sob a qual as formas de viver a cidade que não se adaptem à cidadepátria são interpretadas como "ingovernabilidade", desordem. Sob essa orientação, quando as pesquisas de opinião acerca das obras da Barcelona-92 mostravam significativas críticas, o governo municipal apontou a necessidade de reconduzir a opinião pública (idem, p. 7). O instrumento escolhido para tal recondução foi precisamente aquele da cidade do marketing: uma impressionante ofensiva publicitária promovida por Barcelona Holding Olímpico e pelo Ayuntamiento de Barcelona. Também em Curitiba as políticas de marketing têm procurado reforçar o elo afetivo entre os cidadãos e o projeto de cidade com marcantes campanhas como a do "coração curitibano" nos anos 80 ou, no ano 2000, com a escolha da música-tema cujo fragmento mais reiterado era "quando a gente ama, claro que a gente cuida". Subjacente a essas representações afeto-cidade-cidadão está a idéia de que qualquer pensamento ou ação que ameaça o consenso pode ser representada como desamor à cidade, e não desacordo com o projeto dominante.

O alcance da comunicação como instrumento político desses governos de cidade parece crescente. As estruturas tecnológicas de informação e comunicação são peças-chave na construção do patriotismo de cidade, equipamentos do poder, dispositivos centrais na produção da subjetividade coletiva. O seguinte fragmento, selecionado de entrevista, parece sintetizar a dimensão deste poder: "Lo que ves acá es un peligro. Nosotros tenemos la lista de cuales son las prioridades de los ciudadanos, elaboradas con base en las encuestas de enero. Primera, la vivienda, segunda, el empleo. Si nosotros en febrero hacemos una gran campaña sobre ambiente y calidad de vida, sabemos que la encuesta que hagamos en marzo nos va a traer ese tema como una de las prioridades de la ciudad, de los ciudadanos. Hay una posibilidad de mani- pulación, puedes de hecho cambiar la percepción que tiene el ciudadano de las cosas. Tu inviertes sensaciones que tiene la gente de algo que funciona mal. Tu lo inviertes al mejorar el problema, al actuar, pero inviertes mucho más las opiniones al comunicar que va a mejorar, al saber comunicar" (NAVARRO, 1997).

\section{CONFLITOS, ANTAGONISMOS, TEN- SÕES: PARA ALÉM DA CIDADE-PÁTRIA}

De fato, tanto no caso de Curitiba quanto no caso de Barcelona, as representações tornadas dominantes são cuidadosamente desenhadas para mostrar uma cidade homogênea e apagar as diferenças políticas, culturais, de classe ou de origem étnica presentes no território urbano. Os discursos da cidade-pátria e do consenso-cidadão, da sociedade urbana como um bloco homogêneo sem conflitos de interesses, orientada para um grande objetivo comum, são forjados no interior das políticas urbanas, com o apoio incondicional dos meios e com o uso amplo de variados instrumentos publicitários, atuando como elementoschave na regulação social e no controle político da população. Como expressa López Sánchez: "La homologación del 'todos' a una mayoría normalizada de ciudadanos pretende redundar en la opacidad o desaparición de las contradicciones metropolitanas y en el secuestro del antagonismo, ya que la constitución de esa mayoría normalizada se maneja para invalidar los flujos sociales no capturados en la ilusión colectiva" (LÓPEZ SÁNCHEZ, 1993, p. 110).

Pesquisa qualitativa realizada com jovens de Curitiba, entre 14 e 20 anos mostra alguns dados que indicam de fato um sentimento de exclusão e de mal-estar em relação à cidade, por exemplo, por parte de jovens negros (SALLAS, 1999, p. 52). Se o quadro de referência majoritário, entre os jovens, está extremamente pautado pela ação do marketing das últimas décadas, há porém sinais de resistência e de recusa à reprodução da imagem oficial por parte de alguns setores da população jovem. Indicador expressivo são os dados organizados segundo extrato sócio-econômico e de cor dos entrevistados. Eles revelam que quanto mais pobres e de pele mais escura, menos os jovens gostam da cidade, além de identificarem "a ação violenta da polícia" como o principal problema de Curitiba (idem, p. 56).

A construção das representações é um processo complexo e contraditório. Há nas representações 
dos jovens fortes disjunções e tensões que combinam leituras favoráveis relativas à cidade, positivas para o público externo, com leituras bastante críticas associadas à cidade do cotidiano e aos problemas que diretamente eles vivenciam.

Com efeito, os projetos de renovação urbana orientados para atender aos grandes interesses de mercado, promovidos como necessários para a "inserção competitiva da cidade", caracterizamse pela seletividade. Nesses projetos muitos fragmentos da cidade-metrópole são esquecidos, riscados da modernização. Por outro lado, aqueles fragmentos eleitos como canteiros midiáticos para ilustrar o chamado "renascimento urbano" têm sido espaços reconfigurados social, econômica e culturalmente, representando, para muitos, a destruição de seus próprios modos, divergentes, de viver o urbano.

Assim, os projetos de renovação dos espaços acolhem variados tipos de investimentos imobiliários, culturais e comerciais, redesenhando a geografia e a história social dos lugares. Os espaços renovados são vendidos como espaços "seguros", que vêm restabelecer a ordem, a civilidade, como contraface das áreas estigmatizadas como "decadentes". As representações excludentes reforçam os processos de gentrificação, como uma "revanche contra trabalhadores precarizados, imigrantes, sem-teto" que ameaçam o projeto modernizador (SMITH, 1996). Os processos de rápida valorização desses espaços e o súbito encarecimento da moradia têm, de fato, expulsado as populações pobres das áreas centrais, o que vem ser corroborado por Tello (1994), que evidencia, para o caso de Barcelona, francos processos de expulsão para as periferias metropolitanas ${ }^{14}$.

$\mathrm{O}$ seqüestro do antagonismo passa pela tentativa de neutralização dos conflitos e pelo obscurecimento das manifestações urbanas contrárias aos projetos e obras da renovação. Se

\footnotetext{
14 Rosa Tello (1994, p. 74) mostra que o encarecimento do preço da habitação nos anos que sucederam à denominação de Barcelona como cidade olímpica constituiu-se em fator de homogeneização social e de segregação daqueles segmentos da população que dispõem de pouca ou nenhuma capacidade de endividamento. Segundo a autora, o preço da habitação converteu-se num instrumento de controle social, o qual tende a estreitar as possibilidades de existência de uma cidade plural, do ponto de vista da composição sócio-econômica da população.
}

na cidade-pátria são consentidas apenas as diferenças domesticadas, aquelas que são capturadas pelo espetáculo, ainda assim o urbano não perde sua característica de lugar de contradições e de agregação conflitiva. O mal-estar associável às cidades para além da cidade-pátria pode ser considerado ruído, aviso de irrupções e movimentos sociais com crescente presença política.

\section{CONCLUSÕES: AGENTES E ESTRATÉ- GIAS EM DISPUTA}

Nesta virada de século, o que parece explicar a aproximação de certas políticas urbanas é a orientação dos respectivos governos para a transformação das cidades em mercadorias, junto à transformação da base material das cidades para o novo padrão de acumulação, sob as pressões uniformizadoras dos atores hegemônicos para a realização do mundo atual. Como resposta a essas pressões, os projetos de cidade, os modelos de desenvolvimento construídos pelos governos locais junto a agentes privados com interesses localizados, parecem guardar, de fato, semelhanças significativas.

O esforço político de alguns prefeitos e governos de cidade em vender sucesso e promover a re-invenção dos lugares encontra-se diretamente associado aos arranjos particulares de interesses originados naqueles mercados, que guardam relações com o mercado de cidades. Esse esforço dos governos também está orientado pela necessidade de dar visibilidade internacional a seus projetos e ações urbanas, visando a um trânsito notável junto às agências multilaterais - que, por sua vez, garantirão futuros financiamentos para novos projetos. A construção de imagens-modelo e a conquista de expressão no mercado de cidades torna-se fundamental nesse contexto.

Através de diversas tendências perfilam-se as estratégias contidas nas políticas urbanas, tanto as locais quanto aquelas da agenda urbana internacional: a adaptação técnica do território com a renovação de infra-estruturas de mobilidade e de telecomunicações, a apresentação de algumas experiências de renovação urbana como modelos, a construção de espaços seletivos voltados aos negócios, ao consumo e à habitação.

Os agentes econômicos privados com interesses localizados e a crescente mundialização dos fluxos e conexões relativos aos mercados pressionam os governos locais para o exercício de sua 
capacidade racionalizadora, de modo que os fluxos continuem a operar. Trata-se de um complexo feixe de relações comerciais que incidem na configuração do espaço político para o qual os governos, através de estratégias transescalares nas políticas urbanas, assumem um caráter regulador, sob três aspectos:

a) ideológico: mediante a difusão das estratégias dos organismos internacionais, construção de representações, imagens e discursos associados à reprodução do modus operandi das chamadas "cidades-modelo", venda das cidades enquanto mercadoria;

b) prático: através do caráter instrumental do espaço e dos meios de ação utilizados, o Estado submete o espaço a uma logística que atende a interesses de mercado;

c) tático-estratégico: com a subordinação dos recursos do território urbano aos objetivos políticos de valorização e reordenamento dos diferentes mercados que incidem no lugar.

A visão de mundo dominante que constrói a "cidade da virada de século" procura, a partir da difusão de "modelos", normatizar as cidades, configurá-las de acordo com os parâmetros da cidade competitiva, da cidade-empresa, da cidademercadoria e da cidade-pátria, desconsiderando a complexidade sócio-espacial e a multiplicidade de projetos políticos em cada território urbano. Diante dessa marcada tendência, parece haver um sentido político na análise e desconstrução crítica dos processos que a acompanham, como contribuição do pensamento crítico à possibilidade de representar o espaço de maneira que supere os limites das representações dominantes.

Ainda que o livre jogo político, democrático e plural pareça bastante constrangido pelos dispositivos da ordem urbana associados à cidade-pátria, podem ser identificados comportamentos, manifestações e movimentos que indicam e afirmam que o campo de possíveis ações que é o espaço urbano nunca estará totalmente capturado pelas estratégias de poder de seus governos midiáticos.

Como qualquer cultura tornada hegemônica em certas condições históricas, políticas, técnicas e econômicas, a cultura urbana que hoje parece dominante por certo não é nem será internalizada passivamente. A possibilidade de ela ser negociada, resistida e seletivamente apropriada pelas pessoas no cotidiano está sempre presente, a desafiar a aparente inexorabilidade dos cenários que aponta.

Os movimentos sociais urbanos, em suas lutas e conquistas, demonstram a capacidade de participar desta luta simbólica ao criar um ideário de cidade, de representação de cidade, que disputa o "pensamento hegemônico" sobre a mesma. Partidos políticos e alianças construídas na perspectiva de campanhas para as eleições municipais também têm importante papel na luta simbólica, disputando projetos alternativos de cidade.

Alternativas críticas podem ser também formuladas pelas várias correntes no âmago do denominado pensamento crítico. Pensamos que o campo da produção simbólica, da cultura e da imagem, relacionados dialeticamente com a produção material das cidades, adquirem hoje centralidade no confronto com a leitura hegemônica de cidade.

A possibilidade de confronto vem do notável imbricamento desses campos com o projeto hegemônico, com a leitura dominante de cidade e, principalmente, do fato de se tratarem de campos em disputa (RIBEIRO, 1999). Diante dessa possibilidade de questionamento e confronto, a reflexão abre-se, no campo da cultura, para processos relevantes que precisam ser desvendados: a visão de mundo que sustenta as políticas de marketing urbano, a mercantilização da cultura, o envolvimento da cultura com a promoção de serviços e mercadorias, a inserção da cultura em processos de "gentrificação" - valorização de áreas da cidade e de segmentos sociais em detrimento de outros, a relação entre cultura e reprodução de processos de inclusão-exclusão social.

No campo da imagem, os processos que necessitam de desvendamento parecem ser: a construção de relações entre comunicação, poder e imagem; a mercantilização da imagem da cidade e a circulação do discurso das "cidades-modelo"; as estratégias de difusão de imagens em múltiplas e mutuamente constituídas escalas espaciais; os principais agentes produtores da imagem da cidade e suas relações constituídas através do habitus; a inscrição de filtros sociais e espaciais na organização da imagem da cidade; as práticas materiais e os valores que pressionam para a atualização das imagens; a emergência de leituras e imagens alternativas.

A análise desses campos, ou melhor, o seu desvendamento pode colaborar para que ocorra o necessário refazer do pensamento crítico sobre a 
cidade e, desse modo, ajudar a reinscrever possíveis projetos críticos, capazes de disputar hege- monia na leitura do urbano.

Recebido para publicação em 15 de maio de 2001.

Fernanda Sánchez (fsanchez@usp.br) é Arquiteta e Urbanista pela Universidade Federal do Paraná (UFPR), Doutora em Geografia pela Universidade de São Paulo (USP) e Pesquisadora do Instituto de Planejamento e Pesquisa Urbana e Regional (IPPUR) da Universidade Federal do Rio de Janeiro (UFRJ).

\section{REFERÊNCIAS BIBLIOGRÁFICAS}

AROCA, M. V. \& VILLALONGA, I. 1997. Barcelona a 100. Protagonistas de una nueva generación. Barcelona : Sirpus.

BORJA, J. 1990. Políticas para la ciudad europea de hoy. In : DE FORN, M. \& BORJA, J. (dirs.). Barcelona y el sistema urbano europeo. Barcelona : Ayuntamiento de Barcelona.

(org.). 1995. Barcelona. Un modelo de transformación urbana. Quito : Programa de Gestión Urbana / Oficina Regional para América Latina y el Caribe.

1996. As cidades e o planejamento estratégico. Uma reflexão européia e latino-americana. In : FISCHER, T. (org.). Gestão contemporânea. Cidades estratégicas e organizações locais. Rio de Janeiro : Fundação Getúlio Vargas.

BORJA, J. \& CASTELLS, M. 1997. Local y global. La gestión de las ciudades en la era de la información. Madrid : United Nations for Human Settlements/Taurus/Pensamiento.

BOURDIEU, P. 1998. Contrafogos : táticas para enfrentar a invasão neoliberal. Rio de Janeiro : Zahar.

1999. A economia das trocas simbólicas. $5^{\text {a }}$ ed. São Paulo : Perspectiva.

BOURDIEU, P. \& WACQUANT, L. 2000. La nouvelle vulgate planétaire. Le Monde Diplomatique, Paris, p. 6-7, maio.

DALA STELLA, C. 2000. Riachuelo, 266. Curitiba : Criar.

DUNCAN, J. \& LEY, D. 1993. Place, Culture, Representation. London : Routledge.

FAVB. 1992. La Barcelona de Maragall. Barcelona: Federación de las Asociaciones de Vecinos de Barcelona, n. 10-11, nov.-dez.
FREY, K. 1996. Crise do Estado e estilos de gestão municipal. Lua Nova, São Paulo, n. 37, p.107138.

HARVEY, D. 1993. From Space to Place and Back Again : Reflections on the Condition of Postmodernity. In : BIRD, J. (org.). Mapping the Futures : Local Cultures, Global Change. Londres : Routledge.

LEFEBVRE, H. 1998. The Production of Space. Londres : Routledge.

LÓPEZ SÁNCHEZ, P. 1993. Todos, mayoría y minorías en la Barcelona Olímpica. Economía y sociedad, Madrid, n. 9, p. 103-115.

MASSEY, D. 1993. Power Geometry and a Progressive Sense of Place. In : BIRD, J. (org.). Mapping the Futures : Local Cultures, Global Change. Londres : Routledge.

1999. Spaces of Politics. In : MASSEY, D. (org.). Human Geography Today. Part V : Rethinking Space and Place. Cambridge : Polity Press \& Blackwell Publishers.

NAVARRO, F. 1997. Entrevista com o Coordenador da Dirección de Comunicación Corporativa y Qualitat del Ayuntamiento de Barcelona. Barcelona, 18.dez.

NOVAIS, P. 1999. Uma crítica ao conceito de espaço no planejamento estratégico. In : Anais do VIII Colóquio internacional sobre o poder local : "Poder local e internacionalização : desenvolvimento, (re)configurações organizacionais e estratégias de gestão". Salvador : UFBA/NPGA/NEPOL.

OLIVEIRA, F. L. 1999. A metáfora cidadeempresa no planejamento estratégico de cidades. Cadernos IPPUR, Rio de Janeiro, v. XIII, n. 1, p. 141-162, jan.-jul.

OLIVEIRA, D. 2000. Curitiba e o mito da cidade 
modelo. Curitiba : UFPR.

PARAIRE, P. 1995. Le "village-monde" et son château. Paris : Le temps des cerises éditeurs.

RIBEIRO, A. C. T. 1999. As leituras da cidade. Intervenção como moderadora de mesa. In : Anais do Seminário "Repensando as políticas públicas e a ação na cidade". Rio de Janeiro : Câmara Municipal do Rio de Janeiro/IPPURUFRJ. Documento disponível em CD-rom.

SALLAS, A. L. F. (org.). 1999. Os jovens de Curitiba : desencantos e esperanças. Juventude, violência e cidadania. Brasília : UNESCO.

SÁNCHEZ, F. 1997. Cidade espetáculo : política, planejamento e city marketing. Curitiba : Palavra.

2001. A reinvenção das cidades para um mercado mundial. São Paulo. Tese (Doutorado em Ciências: Geografia Humana). FFLCH, Departamento de Geografia, Universidade de São Paulo.

SÁNCHEZ, F. \& MOURA, R. 1999. Cidades modelo : espelhos de virtudes ou reprodução do mesmo? Cadernos IPPUR, Rio de Janeiro, ano XIII, n. 2, p. 95-114, ago.-dez.

SANTOS, M. 1996. A natureza do espaço. Técnica e tempo, razão e emoção. São Paulo : Hucitec.

2000. Por uma outra globalização : do pensamento único à consciência universal. Rio de Janeiro/São Paulo : Record.

SMITH, N. 1996. The New Urban Frontier: Gentrification and the Revanchist City. London : Routledge.

SOUZA, N. R. 1999. Planejamento urbano, saber e poder : o governo do espaço e da população em Curitiba. São Paulo. Tese (Doutorado em Sociologia). FFLCH, Departamento de Ciências Sociais, Universidade de São Paulo.

TELLO, R. \& MARTINEZ, S. 1994. Terciarização e encarecimento do alojamento em Barcelona. Finisterra, Lisboa, v. XXIX, n. 57, p. 61-77.

TEZZA, C. 2001. Pacato cidadão curitibano. Cristóvão Tezza espelha em 11 livros o conservadorismo pós-moderno do sul. Gazeta Mercantil, São Paulo, 23.fev.

VAINER, C. B. 2000. Pátria, empresa e mercadoria. Notas sobre a estratégia discursiva do planejamento estratégico urbano. In : ARANTES, O., VAINER, C. B. \& MARICATO, E. A cidade do pensamento único : desmanchando consensos. São Paulo : Vozes.

WARD, S. V. 1998. Selling Places. The Marketing and Promotion of Towns and Cities, 18502000. Londres : Routledge.

\section{OUTRAS FONTES}

Barcelona, una passió. 1992. Dirigido por L. Pomés. Barcelona, Ajuntament de Barcelona. Vídeo de difusão oficial., $20 \mathrm{~min}$.
As dez melhores cidades para se fazer negócios. 2000. Exame, São Paulo, ano 34, n. 9, ed. 713, maio. 